Transportation Research Forum

Transportation Model Validation Using Extreme-World Method Scenario Construction Author(s): Heather Shar, Paul Componation, Michael Anderson, and Alisha Youngblood Source: Journal of the Transportation Research Forum, Vol. 48, No. 1 (Spring 2009), pp. 105-116 Published by: Transportation Research Forum

Stable URL: http://www.trforum.org/journal

The Transportation Research Forum, founded in 1958, is an independent, nonprofit organization of transportation professionals who conduct, use, and benefit from research. Its purpose is to provide an impartial meeting ground for carriers, shippers, government officials, consultants, university researchers, suppliers, and others seeking exchange of information and ideas related to both passenger and freight transportation. More information on the Transportation Research Forum can be found on the Web at www.trforum.org. 


\title{
Transportation Model Validation Using Extreme-World Method Scenario Construction
}

\author{
by Heather Shar, Paul Componation, Michael Anderson, and Alisha Youngblood
}

The Alabama Transportation Infrastructure Model (ATIM) is a discrete event simulation of major transportation routes. The model is currently being validated; however, due to limited data and projected changes in traffic patterns, common validation methods (comparison to real-world figures and utilizing historical data to forecast future trends) are impractical. Therefore, an alternative validation approach was developed, using a scenario planning technique known as extreme-world view that allows model developers to test a wider range of model inputs than using limited current or historical data. The model's response to a range of scenarios indicates it tracks expected real-world performance well.

\section{INTRODUCTION}

To date, statewide freight transportation planning has largely relied on trend-line analysis of economic and population data to forecast future facility usage. However, unexpected industry growth and development of new industries in a region can create a much higher transportation demand than would be indicated by historical data. To improve the ability to forecast statewide transportation needs, researchers at The University of Alabama in Huntsville developed the Alabama Transportation Infrastructure Model (ATIM). This is a forward-looking, discrete event simulation model that can be used to evaluate the impact of changing freight patterns to more accurately plan for future transportation infrastructure needs.

Proper use of ATIM will give state officials the ability to rapidly evaluate the impact of development patterns and infrastructure investment decisions on the state's freight transportation system, which includes highways, rail and water routes. As with all modeling techniques, data quality is important for an accurate representation of real world behavior. Unfortunately, the most often used validation technique of comparing model output with actual ground count data is not available to freight modelers, because actual truck counts and flow data are difficult to obtain. Shippers maintain proprietary freight transport logs, but these are rarely available to public entities due to privacy concerns. When freight counts are collected by planning agencies, the data are often suspect because there are no clear guidelines regarding sampling methodology; there is no way of knowing which commodities the freight vehicle carries without interviewing shippers, and the origin and destination points of a shipment can vary due to trip chaining.

This paper reports on efforts to address these model limitations. First, general information on current related transportation models is presented. Then information is provided on a variation of scenario analysis referred to as Extreme-World Scenario construction. This technique was selected because it allows for the development of unique scenarios that include a host of extreme data points at the boundaries of expected performance. Next, information is provided on the development and use of ATIM. The scenarios developed using extreme world views are then run in ATIM and the results discussed. The paper closes with a discussion of the general conclusions drawn from this approach and notes areas for future research. 


\section{LITERATURE REVIEW}

There have been several past initiatives to develop transportation models, some of which provided background for this research. The Virginia Department of Transportation developed a model focused on predicting the future flow of freight and improving the freight flow pattern in the state of Virginia. This was accomplished by developing a GIS database that contained infrastructure data for freight transportation and county demographics. Commodity flow data was obtained on a county basis, and a statistical relationship was established between the production and attraction of freight (Brogan et al. 2001). A Fratar Growth factor model was used to distribute freight from origins to destinations, and a modified growth factor model was used to predict trips and develop ton-to-vehicle conversion factors for future trip distribution.

In a recent study in Mississippi, a prototype simulation model of freight movements was developed (Tan et al. 2003). This model used the Commodity Flow Data, Cargo Density Database (U.S. Department of Transportation 2007) and Vehicle Inventory Use Survey data (U.S. Department of Commerce 1999) as freight inputs. Simulations were performed in TransCAD to predict transportation system performance using the traditional four-step transportation planning process of trip generation, trip distribution modeling, modal split and trip assignment modeling. Additionally, the model contained simulation and animation software to display freight flow movements, change of modes at the terminals and to evaluate the importance of different modes and routes (Tan et al. 2003).

A model developed at the Center for Transportation Research and Education at Iowa State University for the Iowa Department of Transportation uses a layered approach for freight flow projections (Souleyrette et al. 1996). Its basic assumptions are that intercity freight transportation does not lead to congestion, because the loading of traffic is not simultaneous. The demand for truck transportation is assumed not to be the same for different economic regions, i.e., truck traffic interacts independently. The meat packing industry was selected as the layer to demonstrate the model, assuming that freight origins are proportional to the number of persons employed in a region (Souleyrette et al. 1996). The model adopted the four-step planning process, but the trip generation step was skipped because it was predicting future trips. A nationwide freight flow database organized by business economic areas was purchased for use in the model.

There are two new techniques to be added to the current research on transportation modeling. The first is a scenario planning approach known as Extreme-World Method. This technique allows planners to develop scenarios that comprise very optimistic and very pessimistic events, as well as explore the interactions between them. This is helpful when trying to test the effects of longterm planning decisions under conditions of extreme growth. The second technique is the ATIM mentioned earlier, which is a discrete-event simulation model that allows for long-term analysis of planning decisions that address freight handling in the state of Alabama.

In all these transportation modeling efforts, current and past data are used to predict future events, sometimes leading to inaccuracies because their underlying assumptions are questionable (Myers and Kitsuse 2000). An alternative approach is to forecast future events using judgments about the best techniques and the most likely underlying assumptions (Myers and Kitsuse 2000). Scenario planning is a method to analyze anticipated problem situations that have uncontrollable environmental, technical or competitive uncertainties for a range of plausible future situations (Daellenbach and McNickle 2005). To use this method, decision makers often develop optimistic, pessimistic and most likely scenarios.

Extreme-World Method (Goodwin and Wright 2004) constructs scenarios that result from interactions of extreme events. It builds scenarios based on selected elements and trends that are based on an organization's key issues of concern. These scenarios go beyond the normal optimistic and pessimistic by allowing planners to more fully explore the effects of extreme event interactions when there is a high degree of uncertainty about future events. When the consequences of failure in 
the planning processes are significant, it may be essential to evaluate more extreme scenarios even when the probabilities of specific extreme occurrences are small (Daellenbach and McNickle 2005).

ATIM is a new tool based on the Virtual Intermodal Transportation System (VITS) model developed at the National Center for Intermodal Transportation at Mississippi State University (Tan and Bowden 2004). It was developed as a first attempt to use discrete-event simulation to model multiple modes of transportation infrastructure in a single simulation. It is very comprehensive, with features including origin and destination points at each of Alabama's 67 county centers, 14 border points for the highway network, 27 border points for the rail network, 942 centerline miles of interstate highways, 2,766 miles of U.S. highways, 909 miles of state highways, all of the Class I rail lines located in Alabama and the navigable inland waterway system in Alabama. ATIM also includes intermodal transfers between truck, rail and water carriers in Huntsville, Birmingham, Montgomery and Mobile, which are the population and employment centers in the state with intermodal freight handling facilities.

ATIM simulates traffic flows over multiple 24-hour periods. By using discrete-event simulation, it is able to incorporate random variation inherent in transportation systems with the raw traffic data collected by government, industry and academic entities. This random variation is visible in the complex interactions of freight movement across transportation networks and through intermodal transfer points. Freight traffic and passenger automobile traffic are independently calculated and combined to simulate overall traffic flows on the roadways. Railway and waterway transportation systems are also modeled to show the dynamics between multiple shipping modes. ATIM focuses on the high-level interactions between market forces driving freight production and movement on one hand, and the responses of public and private entities to the freight levels generated on the other. As such, it can evaluate the impacts of policy decisions, large-scale capital construction and investments, or market changes on the performance of Alabama's transportation infrastructure and its ability to move goods and people.

An input to ATIM is the expected level of traffic generated by industry clusters. This is obtained from TRANPLAN, an urban-planning model that is based on linear regression models of employment, payroll and the value of shipments at the county level. In this model, employment is an indicator of population growth, and payroll and value of shipments are indicators of economic activity (Shar and Anderson 2006).

\section{METHODOLOGY}

\section{Background}

The most common method of model validation is to compare its output for a known set of inputs to real-world data under similar conditions. However, sparse availability of real-world data limits this type of validation. This limitation is compounded by the fact that ATIM is a representation of a realworld system. This means that it reflects some but not all key parameters observed in real-world situations. Another limitation is the tradeoff between model reliability, ease of development and use. For example, in Alabama the freight route network modeled in ATIM is a subset of the actual roadway system. Hence, all interstate road facilities are in it, but some U.S. highways and many state and county highways are not. Also, some freight carriers familiar with the local road system choose alternate routes that are not in the model. On top of all this, the Alabama Department of Transportation (ALDOT) does not regularly conduct freight surveys to determine the level of freight that moves on given roadways. Although total traffic counts are available for calibration, no data is available to compare the model's output of freight traffic to its actual level. In addition, the structure of ATIM is dependent on free-flow speed being assigned to links. However, detailed roadway data are unavailable to calculate free-flow speeds.

The use of TRANPLAN for the distribution of freight along inter-county roads also creates some key difficulties in validating the model. Among them, TRANPLAN creates a gravity-model 
for distribution, and traffic is assigned to multiple routes based on estimated travel times. In cases of congestion, it assigns traffic to less-preferred routes to minimize system travel time. In the realworld, however, freight will often remain on a pre-determined delivery route despite congestionrelated delays. Another difficulty is that TRANPLAN assumes all traffic in an urban area will behave as passenger car traffic and that each departing trip returns within a 24-hour period. Intercity and interstate freight trips, however, usually do not return to their original locations within 24 hours, if at all. In some traffic planning, lower levels of model reliability are considered acceptable for decision-making purposes than are usually found in other disciplines. For example, a model that provides outputs within a plus or minus $20 \%$ accuracy may be considered acceptable in practice. However, as network traffic volume approaches capacity, the level of reliability required of a model may increase. Currently, there is no consensus on what constitutes an acceptable level of accuracy for transportation models.

\section{Model Validation}

Given these difficulties, the model validation process was split into phased tests requiring different levels of data intensity. The phases include the generation of scenarios, the development of input data for ATIM using the results of the scenario construction and TRANPLAN, running ATIM with the input data and assessing the results to check for model validity. The interest of this paper is the scenario generation and the model's results. The construction of the scenarios is in Table 1. In practice, the steps in the scenario construction are less straightforward because they have feedbacks. This may be partly due to the exploratory nature of the approach of asking decision makers more probing questions versus other forecasting approaches. For example, steps one and two were done initially and then revisited after identifying the impacts of the trends in step four. Step three identifies the uncertainties and was also done initially and revisited after the impacts of those uncertainties were evaluated in the second part of step four. The actual construction of the scenarios took place in steps five through eight, and those actions were taken concurrently for each of the best-case, worstcase and status-quo options. A detailed discussion of the steps follows.

Step 1: The overall issue of concern is the ability of Alabama's transportation system, specifically roadways, waterways and railways, to move goods and people throughout the state to promote economic activity and growth. One measure of transportation system performance with respect to this goal is the amount of congestion and associated delay travelers experience. The ATIM's focus is on "rural" roadways within the state and outside the planning areas of the metropolitan planning organizations. Consequently, the impact of freight vehicles on congestion levels and the associated travel time delays occurring on these roads were most important to the research team. The level of freight traffic also shortens maintenance cycles and forces frequent repaving. For these reasons, freight traffic volume was chosen as the independent variable to be changed in the scenario construction. A higher volume is considered a negative impact, while a lower volume is considered a positive impact. For the ATIM, the dependent variables are the average speed on I- 65 between Montgomery and Mobile, the average speed on I-10 between Mobile and the Mississippi state border, the average speed on I-10 between Mobile and the Florida state border, and the average zone utilization in terms of volume-capacity $(\mathrm{v} / \mathrm{c})$ ratio for each of the Alabama DOT traffic districts. The $\mathrm{v} / \mathrm{c}$ ratio is the total number of trucks in a zone divided by the capacities of all roadway sections within that zone. A five-year period was chosen for predictive purposes, giving a horizon year for testing the ATIM as 2012. This is considered reasonable when dealing with freight patterns, because most manufacturing companies and shippers are fairly comfortable with predicting their growth over five years. Moreover, estimates of future activity beyond five years are unreliable. 
1. Identify the issue of concern and the horizon year that will be captured in the scenarios.

2. Identify predetermined trends that have some degree of impact on the issue of concern.

3. Identify critical uncertainties, which when resolved (one way or the other) have some degree of impact on the issue of concern.

4. Identify the degree to which the trends and unresolved uncertainties have a negative or positive impact on the issue of concern.

5. Create extreme worlds by putting all positively resolved uncertainties in one scenario and all negatively resolved uncertainties in another scenario.

6. Add the predetermined trends to both scenarios.

7. Check for internal coherence. Could the trends and resolved uncertainties co-exist in a plausible future scenario?

8. Add in the actions of individuals and/or organizations that will be impacted by the future described in a scenario. What actions would they take/have taken to satisfy their own interests?

Steps 2 and 4: Table 2 shows the overall trends identified and their impacts on the level of freight on Alabama roadways. These trends represent the consensus of the freight community on the outlook for freight movement at the national and global levels. A literature and database review was done to identify trends that would have an impact on the Alabama transportation network. The qualitative impact of these trends on freight traffic is shown in the last column of Table 2. Using Goodwin and Wright's (2004) notation, a positive or reinforcing impact is denoted by "+ve." A very positive or highly reinforcing impact is denoted by "++ve." Alternatively, a negative or decreasing impact is denoted by "-ve," while a strong negative or greatly decreasing impact is denoted by a "--ve."

Steps 3 and 4: Table 3 shows the key uncertainties identified and their impacts on the level of freight on Alabama roadways. These uncertainties are unique to Alabama and are expected to resolve within the five-year planning horizon. The same designation in Table 2 is used in Table 3 to show the level of impact each uncertainty is expected to have on the freight vehicles in the system. The uncertainty scores were determined by discussions with local and regional transportation professionals who provided information on the range of possible impacts. The uncertainties, by their nature, may have a range of possible impacts. Individual uncertainties are coded for easier tracking using a U1, U2,... sequence as shown in the first column of Table 3 . The upper and lower bound of the uncertainties are then coded using a $\mathrm{u} 1, \mathrm{u} 2, \ldots$ sequence as shown in the third column of Table 3. Some impacts, such as the Kia production facility in Georgia, were judged to have a significant impact on the Alabama transportation network, ranging from a highly reinforcing impact $(++v e)$ to a reinforcing impact $(+v e)$. Other uncertainties had impacts that ranged from reinforcing to decreasing impact. 
T1 Increasing congestion at ports on the eastern and western coastlines

(FHWA 2002)

T2 Increasing volumes of containers

Hayse (2007)

T3 Rising gasoline and diesel prices

Energy Information Administration (2007)

T4 Increased use of air freight to ship time-sensitive cargoes

BC Stats (1996)

T5 Increased levels of just-in-time shipments in manufacturing to retail supply $\quad+v e$ chains

UPS (2005)

T6 Reduced federal funding for roadway maintenance and new construction

U.S. Department of Transportation (2007)

T7 Reduced federal funding for locks and dams and waterway dredging

U.S. Army Corp of Engineers (2007)

T8 Increased production in China and other off-shore locations

Bingham (2006)

T9 Low capital investment in constructing new railroad routes

(Personal communication 2006)

T10 Decreasing ability of railroads to follow short-haul freight routes

(Personal communication 2006)

T11 Increased use of globalized supply chains

$+\mathrm{ve}$ Fujita and Thisse (2006)

Steps 5-8: The three extreme-world scenarios constructed from the uncertainties and trends are in Table 4. They were created by combining all positively resolved uncertainties into the worst-case scenario and all of the negatively resolved uncertainties into the best-case scenario. The overall trends in freight transportation were then added and checked for internal coherence. Given that the ATIM tests high-level policy decisions, the actions of individuals and organizations that would be affected were included in the impacts of the trends and uncertainties. These scenarios were then used in conjunction with TRANPLAN to develop inputs for ATIM. The simulations with the ATIM model based on the three inputs were then reviewed to determine model validity. 
Table 3: Key Uncertainties and Their Impact on Freight Volume

Key Uncertainties

Impact

\begin{tabular}{|c|c|c|c|c|}
\hline $\mathrm{U} 1$ & $\begin{array}{l}\text { Level of container traffic through Choctaw Point } \\
\text { at Port of Mobile }\end{array}$ & $\begin{array}{l}\mathrm{u} 11 \\
\mathrm{u} 12\end{array}$ & $\begin{array}{l}\text { Higher } \\
\text { As Is }\end{array}$ & $\begin{array}{l}++\mathrm{ve} \\
+\mathrm{ve}\end{array}$ \\
\hline \multirow[t]{3}{*}{$\mathrm{U} 2$} & $\begin{array}{l}\text { Level of freight traffic processed through Port of } \\
\text { New Orleans }\end{array}$ & $\mathrm{u} 21$ & Higher & --ve \\
\hline & & $\mathrm{u} 22$ & As Is & $+\mathrm{ve}$ \\
\hline & & $\mathrm{u} 23$ & Lower & $++\mathrm{ve}$ \\
\hline \multirow[t]{2}{*}{$\mathrm{U} 3$} & Implementation of freight-only toll lanes & $\mathrm{u} 31$ & Implemented & -ve \\
\hline & & $\mathrm{u} 32$ & Not Implemented & $+\mathrm{ve}$ \\
\hline \multirow[t]{3}{*}{ U4 } & Number of available truck drivers & $\mathrm{u} 41$ & More & $+\mathrm{ve}$ \\
\hline & (due to legal requirements, economic growth, & $\mathrm{u} 42$ & Current Level & -ve \\
\hline & changing demographics, etc.) & $\mathrm{u} 43$ & Less & --ve \\
\hline \multirow[t]{2}{*}{ U5 } & Kia facility production in Georgia & u51 & Higher & $++\mathrm{ve}$ \\
\hline & & u52 & Lower & + ve \\
\hline
\end{tabular}

One criticism of forecasting is the overall acceptability of its assumptions (Wachs 2001). Core assumptions and judgments are often not made clear to the public or to the decision makers (Myers and Kitsuse 2000). The extreme-world view approach addresses this issue by identifying and referencing the sources of the trends in Table 2, as well as identifying the key uncertainties in Table 3 that impact future scenarios. The scenario construction in Table 4 drew directly from these trends and key uncertainties. The multiplicative effects of this process resulted in scenarios that are more extreme than scenarios developed with traditional scenario planning techniques. The data collected to support the scenarios was comprehensive but still open to interpretation.

The three scenarios, lowest, highest and the historical trend projected volume all generated much higher levels of variability than traditionally seen using only historical trend data. The ATIM program used the traffic levels generated from the three extreme-world scenarios, and it was run for five days of simulated weekday time. At the end of each run, output data were collected and average speed on the interstates and zone utilization were used to check for model validity.

The average speed on interstates was checked for I-65 between Mobile and Montgomery (northbound), I-10 between Mobile and the Florida border (eastbound), and I-10 between Mobile and the Mississippi border (westbound). The zone utilization for the nine ALDOT traffic districts was also checked. Average speed was used as a variable to test the impact of congestion on traffic. The expected response for average speed is a decrease, as traffic volume rises because of congestioninduced slowdowns. Zone utilization was chosen because it is an aggregate measure of the volumeto-capacity ratio for a region. The expected response for zone utilization is an increase, followed by a plateau as the volume of traffic increases and eventually exceeds the available roadway capacity. 


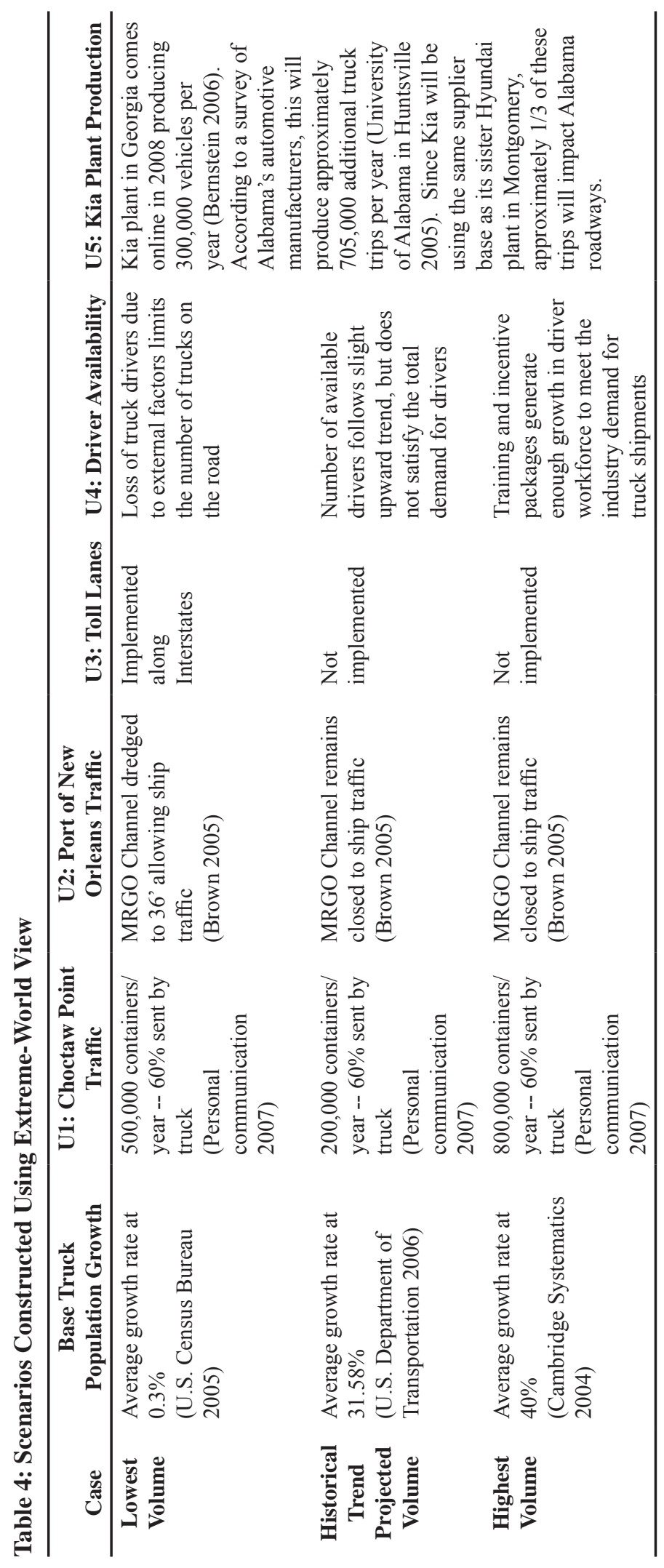




\section{RESULTS}

The analysis examined two output variables from the model - average speed and zone utilization. The variables were reviewed at three choke points on the Alabama interstate system. Table 5 shows the average speeds experienced by traffic on the selected roadway segments during the three model runs. The outputs for I-65 and I-10 are important because these routes are used by freight traffic originating at the Choctaw Point facility at the Port of Mobile. I-10 West showed a decrease in average vehicle speed of $2.2 \mathrm{mph}$, or $3.4 \%$ from the best-case to the worst-case scenario. I-10 East showed a decrease in the average vehicle speed of $3.7 \mathrm{mph}$, or $5.7 \%$ from the best-case to the worstcase scenario. I-65 Northbound showed the greatest decrease, $4.3 \mathrm{mph}$ or $7.17 \%$, which is to be expected since a high percentage of the traffic generated by the Choctaw Point container handling facility at the Port of Mobile uses this road to reach the I-85 interchange in Atlanta and the I-20 and I-59 interchanges in Birmingham.

Table 5: Average Speed (mph) of Selected Roadway Segments

\begin{tabular}{lccc}
\hline Scenario & I-65 Northbound & I-10 West & I-10 East \\
\hline Best-Case & 59.73 & 64.95 & 64.00 \\
Status Quo & 57.08 & 63.14 & 61.50 \\
Worst-Case & 55.44 & 62.75 & 60.34 \\
\hline
\end{tabular}

The second variable, zone utilization, was based on the nine traffic districts designated by ALDOT. Alabama's counties are broken into nine districts by the state Department of Transportation for planning purposes. The results for zone utilization in Table 6 show that the v/c ratio increased as we moved from the best-case to the status quo and on to the worst-case scenario. The change was more pronounced from the best-case to the status quo, averaging about $13.65 \%$ compared to the average increase between the status quo and the worst-case scenario of $3.81 \%$. This suggests that the capacities of the roadways are being filled, and continuing to add more traffic would not increase utilization. Zone 9, where the Port of Mobile is located, saw no increase in utilization between the status quo and the worst-case scenarios, even though additional traffic was added to the roadway volume. This suggests that Zone 9 has reached the saturation point, where the roadways cannot accommodate additional vehicles, resulting in high levels of congestion and long delays.

Table 6: Zone Utilizations (Volume to Capacity Ratios)

\begin{tabular}{cccc}
\hline & Best-Case & Status Quo & Worst-Case \\
\hline Zone 1 & 1.17 & 1.38 & 1.44 \\
Zone 2 & 0.42 & 0.51 & 0.54 \\
Zone 3 & 2.09 & 2.36 & 2.45 \\
Zone 4 & 0.90 & 1.08 & 1.16 \\
Zone 5 & 1.43 & 1.62 & 1.69 \\
Zone 6 & 1.32 & 1.49 & 1.55 \\
Zone 7 & 0.47 & 0.53 & 0.55 \\
Zone 8 & 0.53 & 0.61 & 0.62 \\
Zone 9 & 2.44 & 2.92 & 2.92 \\
\hline
\end{tabular}

To fully develop the model procedure, additional work will be required. While the extremeworld view scenarios and the ATIM itself are concerned with freight volumes and transportation infrastructure resources, neither provides any feedback on how they are connected to Alabama's 
economic activity. High freight levels indicate high economic activity and the distribution of goods and raw materials throughout the region and the country. At some point, however, those high freight levels discourage additional regional growth, because the transportation system lacks the capability to absorb more traffic. At that point, freight level becomes an impediment rather than a symptom of a highly performing economy. Conversely, low freight levels are good because they encourage further expansion into an area. But, if they are too low, they indicate a poorly functioning economy. Further research is needed to describe the conditions under which freight levels become a liability instead of an asset and how targeted changes to the infrastructure can enable economic growth.

\section{CONCLUSIONS}

The application of ATIM using the three scenarios gave results consistent with expectations. Detailed data-intensive model calibration and validation still need to be done at the roadway link and corridor levels. The general performance of the simulation demonstrates that the overall structure and logic of the model are appropriate for the research questions asked. The extreme-world scenarios were used successfully to apply the ATIM, and the results were as expected. Several questions need to be answered before a more data-intensive validation is attempted. They include: What are the appropriate replication parameters to obtain repeatable results? Is there a difference between running single replications of multiple-day time periods and running multiple replications of single-day time periods? Why does the model's zone utilization exceed one, unlike traditional volume-to-capacity ratios, without resulting in congestion-induced roadway shut-down? At what level of traffic saturation does zone utilization stop increasing? Is that level the same for all zones, or does it depend on the mix of differing roadway types available in the prescribed area? If one zone reaches saturation, how does that affect the rest of the roadway system? Does it make a difference if the saturated zone contains a major freight generator or a major arterial?

After the questions about the model behavior are answered, more detailed validation is necessary to bring the ATIM to the performance level expected by ALDOT and metropolitan planning organizations. Areas for further model development include: calibration of the model-generated traffic trips to known trip levels; linking freight traffic levels on the waterway and railway systems; integration of urban freight data from the MPOs into the model; development of intermodal transfer volumes; and further scenario refinement beyond the extreme cases to show the impact that targeted changes can have on overall system behavior.

\section{References}

American Public Transit Association. www.apta.com/research/stats/bus/buscost.cfm (accessed August 29, 2005).

BC Stats. "Feature: Air Freight Use Growing with High Value Exports." 1996. www.bcstats.gov. bc.ca/pubs/exp/exp9603.pdf (accessed March 2007).

Bernstein, M. “Kia’s New Plant.” Businessweek, (October 2006), www.businessweek.com/autos/ content/oct2006/bw20061025_587181.htm?chan=innovation_auto+design_design+strategy (accessed February 2007).

Bingham, P. "Freight Transportation Megatrends," TRB Freight Demand Modeling Conference, Washington D.C., 2006.

Brogan, J.J., S.C. Brich, and M.J. Demetsky. "Application of a Statewide Intermodal Freight Planning Methodology.” Final Report for Virginia Department of Transportation, 2001. 
Brown, M. “Corps Suspends Plans to Dredge MGRO.” The New Orleans 'Times-Picayune, 2005. www. nola.com/newslogs/breakingtp/index.ssf?/mtlogs/nola_Times-Picayune/archives/2005_11_21.html (accessed February 2007).

Cambridge Systematics, Inc. "Traffic Congestion and Reliability: Linking Solutions to Problems." 2004. http://ops fhwa.dot.gov/congestion_report_04/congestion_report.pdf (accessed February 2007).

Daellenbach, H.G. and D.C. McNickle. Management Science: Decision Making Through Systems Thinking. Palgrave MacMillan, New York, 2005.

Energy Information Administration. "Price Summary." http://www.eia.doe.gov/emeu/steo/pub/ contents.html\#Global_Petroleum_Markets (accessed March 2007).

FHWA Freight Management and Operations. "Freight Information Real-Time System for Transport (FIRST).” 2002. http://ops.fhwa.dot.gov/freight/freight_news/first/first htm (accessed March 2007).

Fujita, M. and J. Thisse. "Globalization and the Evolution of the Supply Chain: Who Wins and Who Loses?” International Economic Review 47(3), (2006): 811-836.

Goodwin, P. and G. Wright. Decision Analysis for Management Judgment, Third Edition. John Wiley \& Sons, Ltd., West Sussex, 2004.

Hayse, J.D. "High Growth in a Logistics-Heavy Economy." Presented at the Transportation Research Board 86th Annual Meeting, Washington, D.C. 2007.

Myers, D. and A. Kitsuse. "Constructing the Future in Planning: A Survey of Theories and Tools." J. Plan. Ed. Res. 19(3), (2000): 221-231.

Shar, H. and M. Anderson. "Discrete Event Simulation of Forecasted Non-Urban Freight Movement." Proceedings of the Transportation Research Board Committee ADA30 Tools of the Trade. 10th National Conference on Transportation Planning for Small \& Medium Sized Communities, Nashville TN, 2006.

Souleyrette, R.R., Z.N. Hans, and S. Pathak. Statewide Transportation Planning Model and Methodology Development Program. Final Report Submitted to Iowa Department of Transportation, 1996.

Tan, A.C. and R.O. Bowden. The Virtual Intermodal Transportation System (VITS). Final Report to the National Center for Intermodal Transportation, Mississippi State University, 2004.

Tan, A., R. Bowden, and Y. Zhang. A Virtual Simulation of Statewide Intermodal Freight Traffic. Final Report Submitted to Mississippi Department of Transportation, 2003.

UPS Supply Chain Solutions. “A Just in Time Supply Chain?” 2005. http://ups-scs.com/solutions/ white_papers/wp_JIT.pdf (accessed March 2007).

U.S. Army Corps of Engineers. "Civil Works Budgeted \$4.8 Billion in FY08.” 2007. www.hq.usace. army mil/cepa/pubs/mar07/story1 htm (accessed March 2007).

U.S. Census Bureau, Population Division. Interim State Population Projections, Internet Release Date: April 21, 2005. "Table A1: Interim Projections of the Total Population for the United States and States: April 1, 2000 to July 1, 2030.” Available online at www.census.gov/population/projections/ SummaryTabA1.pdf (accessed March 2007). 
Transportation Model Validation

U.S. Department of Commerce. 1997 Economic Census Vehicle Inventory and Use Survey, April, 1999.

U.S. Department of Transportation. 2007 Budget in Brief. www.dot.gov/bib2007/tables html\#br (accessed March 2007).

U.S. Department of Transportation. 2007 Commodity Flow Survey Advance Data File, www. census.gov/svsd/www/cfsmain html (accessed March 2007).

U.S. Department of Transportation Federal Highway Administration, Office of Freight Management and Operations. "Freight Facts and Figures." 2006.

Wachs, M. "Forecasting Versus Envisioning: A New Window on the Future." Journal of American Planning Association 67(4), (2001), 367-372.

\section{Acknowledgements}

This project was funded in part by U.S. Department of Transportation, Office of the Secretary, Grant No. DTOS59-05-G-00021. Additional funding was provided by the U.S. Department of Transportation, Federal Transit Administration, Project Number FTA-AL-26-7262.

Heather Shar is a research associate in the Office of Economic Development at the University of Alabama in Huntsville. She obtained a bachelor's degree in industrial and systems engineering from the University of Alabama in Huntsville and a master's degree in systems engineering. Her background is in continuous process improvement and lean manufacturing engineering. She is an engineer intern, certified by the Alabama State Board of Licensure.

Paul Componation is a professor of industrial and management systems engineering with the University of Alabama in Huntsville. He has consulted in product and system development. His primary research interests are in systems development, decision analysis and economics. He is a senior member of the Institute of Industrial Engineers and a fellow with the American Society for Engineering Management.

Michael Anderson has spent many years teaching and performing research in the area of travel modeling. He is an associate professor of civil engineering at the University of Alabama in Huntsville. He received his Ph.D. in civil engineering with a focus in transportation engineering from Iowa State University.

Alisha Youngblood is a visiting assistant professor with Worcester Polytechnic Institute. She earned B.S., M.S, and Ph.D. degrees in industrial engineering from the University of Arkansas. Her research interests include engineering management, performance measurement, economic decision analysis and logistics. She is an active member of the Institute of Industrial Engineers and the American Society for Engineering Management. 